\title{
ANÁLISE DA ARBORIZAÇÃO DE PRAÇAS DO MUNICÍPIO DE NOSSA SENHORA DO SOCORRO - SE
}

\author{
SQUARES AFFORESTATION ANALYSIS OF NOSSA SENHORA DO SOCORRO \\ $C I T Y-S E$
}

\author{
Janisson Batista de Jesus ${ }^{1}$, Raimundo Renato Valença Junior², Anabel Aparecida de Mello², \\ Robério Anastácio Ferreira ${ }^{4}$
}

\section{RESUMO}

A cidade é um espaço territorial complexo e dinâmico que compreende vários processos relacionados à urbanização, resultando na redução de suas áreas verdes. Neste contexto, as praças tornam-se uma das melhores opções na tentativa de proporcionar um equilíbrio entre a natureza e as cidades. $\mathrm{A}$ pesquisa foi realizada com o objetivo de analisar a composição florística e a estrutura fitossociológica da vegetação arbórea das principais praças do município de Nossa Senhora do Socorro-SE, visando contribuir com mais informações para um adequado planejamento e gestão destes ambientes. Para a realização da análise da vegetação foi realizado um censo em 21 praças do município. 0 reconhecimento das espécies arbóreas foi realizado por meio da coleta de material botânico, confecção de exsicatas e consultas à literatura especializada. Para a análise dos parâmetros fitossociológicos foram coletadas informações de diâmetro à altura do peito (DAP), medido a 1,30 m de altura do solo, e altura total de cada indivíduo, dados estes processados no software Mata Nativa 2. Foi cadastrado um total de 271 indivíduos pertencentes a 17 espécies, distribuídas em 12 famílias botânicas e em 17 gêneros. Do total de espécies encontradas, 70,5 \% são exóticas e 29,5 \% são nativas.

Palavras-chave: Planejamento urbano; Áreas verdes; Espécies florestais.

\section{ABSTRACT}

The city is a complex and dynamic territorial space comprising several processes related to urbanization, resulting in the reduction of its green areas. In this context, the squares become one of the best options in an attempt to provide a balance between nature and cities. The survey was carried out to analyze the floristic composition and the phytosociological structure of urban trees in the main squares in the city of Nossa Senhora do Socorro - SE, to contribute with more information for planning and management of these environments. To carry out the analysis of the vegetation a census in 21 squares of the city was taken. The identification of tree species was realized by collecting botanical material, making herbarium specimens and consulting specialized literature. For the phytosociological analysis the diameter at breast height $(\mathrm{DBH})$, at $1.30 \mathrm{~m}$ from the floor, and total height of each individual were measured and the data was processed in the Native Forest 2 software. A total of 271 individuals belonging to 17 species, distributed in 12 botanical families and 17 genera were registered. Of the species found, $70.5 \%$ are exotic and $29.5 \%$ are native.

Keywords: Urban planning; Green areas; Forest species.

Recebido em 04.07.2015 e aceito em 13.10.2015

1 Engenheiro Florestal, Mestre pelo Programa de Pós-Graduação em Agricultura e Biodiversidade da Universidade Federal de Sergipe. São Cristóvão/SE Email: janisson-batista-de-jesus@hotmail.com

2 Engenheiro Florestal, Universidade Federal de Sergipe. São Cristóvão/SE Email: rrvj99@yahoo.com.br

3 Engenheira Florestal, Dr., Professor do Departamento de Ciências Florestais da Universidade Federal de Sergipe. São Cristóvão/SE Email: anabel_mello@yahoo.com.br

4 Engenheiro Florestal, Dr., Professor do Departamento de Ciências Florestais da Universidade Federal de Sergipe. São Cristóvão/SE Email: roberioaf@yahoo.com.br 


\section{INTRODUÇÃO}

O surgimento da maioria das grandes cidades brasileiras aconteceu de forma muito rápida, que, com uma expansão populacional desenfreada junto à falta de planejamento resultou em um ambiente urbanizado com diversos problemas ambientais (MORAES; GOUDARD; OLIVEIRA, 2008).

A velocidade e a intensidade da urbanização no Brasil, não é o ponto chave do seu processo, mas sim a forma irregular e desordenada de como isto acontece, o que resulta em vários problemas (GROSTEIN, 2001). Com o seu advento, ocorre entre outras consequências, grande pressão sobre as áreas naturais, o qual promove a substituição dos ecossistemas naturais equilibrados por ambientes artificiais ecologicamente desequilibrados.

Como alternativa para reduzir esse contraste, segundo Toledo e Santos (2008), as praças por serem geralmente constituídas por áreas verdes se tornam um ambiente bastante indicado uma vez que são importantes na qualidade de vida da população e na redução de impactos ambientais urbanos.

Para que as praças possam cumprir suas funções no ambiente urbano, estas devem ser bem projetadas e geridas, buscando adotar práticas que visem à melhoria das condições do meio, a fim de se conseguir um ambiente ecologicamente e fisicamente equilibrado, procurando minimizar os efeitos prejudiciais existentes e, para isso, deve-se ter um amplo conhecimento das características das espécies arbóreas empregadas e da infraestrutura da praça (SERRANO et al., 2010).

De acordo com Freitas e Magalhães (2012), por meio da realização do inventário quali-quantitativo da arborização é possível conhecer a composição florística e sua estrutura, analisar as suas relações interespecíficas com o meio ambiente, e ainda, contabilizar com precisão o número total de árvores de praças.

Portanto, é imprescindível para um bom planejamento da arborização urbana, conhecer e avaliar a constituição arbórea das praças por meio de inventários realizados com uso de diferentes metodologias (REDING et al., 2010; COLETTO; MÜLLER; WOLSKI, 2008), os quais permitem identificar as espécies já implantadas, verificar os possíveis conflitos com os outros componentes urbanos e promover a implantação de novas espécies florestais.

A cidade de Nossa Senhora do Socorro é uma das mais desenvolvidas do Estado de Sergipe, com uma grande ocupação populacional e poderio industrial, considerada parte da Grande Aracaju.

Assim, as praças se tornaram importantes obras que, ao longo do tempo, estruturaram a cidade e proporcionaram uma das poucas áreas com espaços naturais. 
Segundo Dantas e Souza (2004), a arborização urbana possui um destaque crescente, em função dos benefícios que proporciona à população e até mesmo devido aos problemas existentes em função da presença das árvores no contexto da cidade, como por exemplo, a disputa da área urbana com outras edificações, redes elétricas e esgoto.

A pesquisa foi realizada com o objetivo de conhecer a composição florística e a estrutura fitossociológica da vegetação arbórea nas principais praças do município de Nossa Senhora do Socorro-SE, a fim de contribuir com maiores informações a respeito das espécies empregadas e servir como base para a implantação e gestão de novas praças na região.

\section{MATERIAL E MÉTODOS}

O presente estudo foi realizado no município de Nossa Senhora do Socorro, Estado de Sergipe, as coordenadas geográficas UTM X: 702611,234144 e Y: 8798508,13752 como centróides. Situado na microrregião do litoral sul sergipano e inserido no Vale do Cotinguiba. O município limita-se com as cidades de Laranjeiras, São Cristóvão, Santo Amaro das Brotas e Aracaju.

Possui uma população de aproximadamente 160.827 habitantes e uma área de $156,7 \mathrm{~km}^{2}$, que corresponde a 0,7\% da área estadual e a 7,4\% da região da Grande Aracaju (SOCORRO, 2011). A densidade demográfica é de 1.025,88 hab/km² (IBGE, 2011a).

O clima da região é caracterizado por ser quente e úmido, com um a três meses secos, além de moderado inverno caracterizado por um período de chuva entre os meses de março a agosto, com uma precipitação anual média de $1.689,0 \mathrm{~mm}$ e uma temperatura média de $25,2^{\circ} \mathrm{C}$ (SOCORRO, 2011). A classe de solo de maior abrangência geográfica no município é a do Podzólico vermelho amarelo (EMBRAPA, 2010).

A vegetação original da região é a Mata Atlântica (IBGE, 2011b), com destaque para os manguezais que margeiam os rios do Sal, Cotinguiba e Sergipe.

O inventário da arborização foi realizado por meio de um censo quali-quantitativo do componente arbóreo, durante os meses de setembro a novembro de 2011, nas 21 principais praças do município de Nossa Senhora do Socorro (Tabela 1), escolhidas mediante um censo composto de 28 praças fornecido pela prefeitura. Destas, foram selecionadas as praças em cada bairro de todo o município, afim de englobar todo o território, sendo que os bairros mais populosos tiveram mais áreas amostradas. Com o intuito de analisar aquelas existentes nos conjuntos habitacionais mais populosos ou daqueles que apresentam maior grau de urbanização. 
Tabela 1. Praças cadastradas, com respectivos conjuntos habitacionais, área e coordenadas geográficas do município de Nossa Senhora do Socorro - SE

Table 1. Squares registered, with their housing groups, area and geographic coordinates in Nossa Senhora do Socorro, SE

\begin{tabular}{|c|c|c|c|}
\hline Nome & Conjunto habitacional & $\begin{array}{l}\text { Área } \\
\left(\mathrm{m}^{2}\right)\end{array}$ & $\begin{array}{c}\text { Coordenadas geográficas } \\
\text { (UTM) }\end{array}$ \\
\hline Praça José Barreto Prado & Fernando Collor de Melo & 3.010 & $0708450-8798746$ \\
\hline Praça Humberto Sena & Fernando Collor de Melo & 6.734 & $0708437-8799050$ \\
\hline Praça da rua 5 & Fernando Collor de Melo & 2.993 & $0708522-8799161$ \\
\hline Praça Geraldo de Assis Silva & Fernando Collor de Melo & 2.094 & $0708485-8799465$ \\
\hline $\begin{array}{c}\text { Praça da Igreja São Marcos } \\
\text { Evangelista }\end{array}$ & Marcos Freire I & 4.880 & $0710947-8800034$ \\
\hline Praça Três Inocentes & Marcos Freire I & 2.646 & $0710991-8800064$ \\
\hline Praça Leandro Silva de Souza & Marcos Freire I & 5.426 & 0710948- 8799844 \\
\hline $\begin{array}{c}\text { Praça do Hospital José do Prado } \\
\text { Franco }\end{array}$ & Marcos Freire I & 1.077 & $0711152-8799866$ \\
\hline Praça Laércio Miranda & Marcos Freire I & 3.055 & $0710861-8800237$ \\
\hline Praça da Mangabeira (Mutirão) & João Alves Filho & 4.526 & $0709239-8798504$ \\
\hline Praça do Colégio Maria de Lourdes & João Alves Filho & 1.818 & $0709412-8798613$ \\
\hline Praça do SAMU & João Alves Filho & 370 & $0709718-8798879$ \\
\hline Praça do Supermercado Todo Dia & João Alves Filho & 1.239 & $0709775-8798857$ \\
\hline Praça Hilton Lopes (Praça Central) & João Alves Filho & 6.300 & $0709680-8799020$ \\
\hline Praça do Restaurante Popular & João Alves Filho & 6.252 & $0709789-8799683$ \\
\hline Praça do CEME & Marcos Freire II & 703 & $0711908-8799876$ \\
\hline Praça Antony Fernandes & Marcos Freire II & 6.702 & $0712201-8799892$ \\
\hline $\begin{array}{l}\text { Praça da Capela Nossa Senhora do } \\
\text { Carmo }\end{array}$ & Albano Franco & 8.702 & $0711610-8801218$ \\
\hline Praça do Final de Linha & Marcos Freire III & 5.341 & $0709728-8802033$ \\
\hline Praça da Avenida A-51 & Marcos Freire III & 5.822 & $0710171-8801576$ \\
\hline Praça Santa Rosa Mística & Jardim & 1.296 & $0702516-8794905$ \\
\hline
\end{tabular}

Para a análise fitossociológica foram coletados os dados de diâmetros à altura do peito (DAP) medido a 1,30 m acima do nível do solo de todos os fustes, utilizando-se fita métrica, e a altura total de cada indivíduo foi obtida com o auxílio de um clinômetro.

Para o reconhecimento florístico foi realizada a coleta do material botânico existente, confecção de exsicatas e, posteriormente, consultas a literaturas especializadas, sendo a classificação taxonômica realizada com base no APG III (2009), por meio da REFLORA (2012).

Os dados coletados foram processados no software Mata Nativa 2, instalado no Departamento de Ciências Florestais e licenciado para a Universidade Federal de Sergipe.

Através desse programa pôde-se analisar a florística dos indivíduos e os seus seguintes parâmetros fitossociológicos: $\mathrm{DA}=$ densidade absoluta; $\mathrm{DR}=$ densidade relativa; $\mathrm{FA}=$ frequência absoluta; $\mathrm{FRi}=$ frequência relativa; $\mathrm{Do} A \mathrm{~B}=$ dominância absoluta; $\mathrm{DoR}=$ dominância relativa; IVI= índice de valor de importância e IVI = Índice de Valor de Importância (\%). De acordo com Moreira (2007) os parâmetros podem ser definidos e calculados da seguinte forma: 
a) Densidade (D): refere-se ao grau de participação das diferentes espécies identificadas na comunidade vegetal.

a.1) Densidade absoluta (DAi): este parâmetro expressa o número de indivíduos de uma espécie com relação a uma unidade de área e é dado por $\mathrm{DAi}=\mathrm{Ni}$, onde DAi é densidade absoluta da espécie i e Ni o número de indivíduos da espécie i.

a.2) Densidade relativa (DRi): a densidade relativa, que é expressa em porcentagem, é a relação entre o número de indivíduos de uma determinada espécie (Ni) e o número de indivíduos de todas as espécies $(\mathrm{N})$, sendo representada por:

$$
\mathrm{DR} i=\frac{\mathrm{DA} \mathrm{i}}{\sum \mathrm{DA} \mathrm{i}}
$$

onde:

$\mathrm{DA}=$ densidade absoluta de cada espécie

$\Sigma \mathrm{DA} i=$ densidade absoluta de todas as espécies

b) Dominância (Do): é definida como a taxa de ocupação do ambiente pelos indivíduos de uma espécie e é normalmente representada pela área basal.

b.1) Dominância Absoluta (DoABi): a dominância absoluta da espécie é calculada com base na área basal.

$$
\mathrm{DoABi}=\frac{\mathrm{ABi}}{\mathrm{ha}}
$$

onde:

$$
\begin{aligned}
& \left.\mathrm{ABi}=\frac{\pi \cdot \mathrm{DAP}^{2}}{40000} \text { (área basal }\right) \\
& \mathrm{ha}=\text { unidade de área }
\end{aligned}
$$

b.2) Dominância Relativa (DoRi): expressa em porcentagem, representa a relação entre a área basal absoluta de uma determinada espécie $(\mathrm{ABi})$ e a área basal absoluta de todas as espécies.

$$
D o R i=\left(\frac{A B i}{\Sigma A B i}\right) \mathrm{X} 100
$$

onde:

$\mathrm{ABi}=$ área basal

$\sum \mathrm{Abi}=$ área basal de todas as espécies 
c) Freqüência $(F)$ : é dada pela probabilidade de se encontrar uma espécie numa unidade de amostragem e o seu valor estimado indica o número de vezes que a espécie ocorre, num dado número de amostras.

c.1) Freqüência absoluta (FAi): expressa o percentual calculado considerando o número de parcelas em que determinada espécie ocorre (OCi) e o número total de parcelas amostradas (UA).

$$
\mathrm{FAi}=\left(\frac{\mathrm{OCi}}{\mathrm{UA}}\right) \mathrm{X} 100
$$

onde:

$\mathrm{OCi}=$ número de unidades amostrais em que $\mathrm{i}$ ocorre.

$\mathrm{UA}=$ número total de unidades amostrais.

c.2) Freqüência relativa (FRi): essa freqüência é o valor percentual calculado para OCi de cada espécie em relação à freqüência total ( $\left.\sum O C i\right)$, que é o somatório de todos as OCi.

$$
\mathrm{FRi}=\left(\frac{\mathrm{OCi}}{\Sigma \mathrm{OCi}}\right) \mathrm{X} 100
$$

onde:

$\mathrm{OC} \mathrm{i}=$ número de unidades amostrais em que $\mathrm{i}$ ocorre.

$\Sigma \mathrm{OCi}=$ somatória de ocorrências para todas as espécies.

d) Índice de Valor de Importância (IVI): expressa a importância ecológica da espécie no ambiente, sendo calculado pela soma da densidade relativa, da dominância relativa e da freqüência relativa.

$$
\mathrm{IVI}=\mathrm{DRi}+\mathrm{DoRi}+\mathrm{FRi}
$$

onde:

$\mathrm{DR} \mathrm{i}=$ densidade relativa .

DoRi $=$ dominância relativa .

$\mathrm{FRi}=$ freqüência relativa. 


\section{RESULTADOS E DISCUSSÃO}

\section{Análise florística}

Considerando-se as 21 principais praças inventariadas, foi encontrado um total de 271 indivíduos pertencentes a 17 espécies, distribuídas em 12 famílias e em 17 gêneros (Tabela 2).

As famílias que apresentaram o maior número de espécies foram: Anacardiaceae com 3 espécies e a Fabaceae (Faboideae), Fabaceae (Mimosoideae), Myrtaceae e Palmae com 2 espécies cada uma. As outras famílias contribuíram com apenas uma espécie cada para a composição da diversidade florística nas praças.

Analisando-se a quantidade de indivíduos por espécie, verifica-se que as mais representativas foram: Ficus retusa (142), Terminalia catappa (38), Pithecellobium dulce (23) e Cocos nucifera (17), representando $81,18 \%$ do número total de indivíduos. Por outro lado, as menos incidentes são Acacia mangium, Anacardium occidentale, Corymbia citriodora, Hibiscus pernambucensis, Pritchardia pacifice e Schinus terebinthifolius, com a presença de apenas um indivíduo.

Das 17 espécies identificadas, verifica-se uma predominância de espécies exóticas (70,5\%), ou seja, originadas de outros países. Apenas 5 espécies encontradas em todas as praças analisadas são nativas do próprio território brasileiro.

Comparando-se o resultado desse trabalho com estudos semelhantes, constata-se a pouca diversidade florística das praças do município de Nossa Senhora do Socorro, com pouca variação na utilização de diferentes espécies para a sua arborização, uma vez que Roxo, Bicudo e Diniz (2009) encontraram em apenas uma, Praça Coronel Moura, na cidade de Botucatu em São Paulo, 11 espécies, o que representa quase o total de espécies encontradas nas 21 praças analisadas no presente estudo.

Souza et al. (2011) realizaram um inventário nas 22 praças em Aracaju, cidade vizinha à Nossa Senhora do Socorro, e encontraram 1.290 indivíduos, distribuídos em 20 famílias botânicas, 46 gêneros e 64 espécies, sendo que destas, nove não foram identificadas. Dessa forma, percebe-se a grandeza do número de espécies utilizadas na arborização das praças do município de Aracaju, limítrofe ao município analisado no presente trabalho.

Brito et al. (2012) encontraram 149 indivíduos pertencentes a 19 espécies arbóreas em 5 praças públicas da cidade de Bom Jesus, Sul do Estado do Piauí, valores estes que comparado ao do presente estudo mostram uma menor quantidade de indivíduos, porém 
com maior diversidade florística mesmo em um levantamento com muito menos unidades amostrais.

Já Tischer, Forte e Pedroso-de-Moraes (2014) ao realizarem um censo em apenas 3 praças do município de Leme-SP, observaram um total de 333 indivíduos distribuídos em 62 espécies divididas em 24 famílias, constatando-se a heterogeneidade da arborização no localidade e a manutenção da diversidade florística com $64 \%$ de espécies nativas.

Tabela 2. Família botânica, nome científico, nome popular e origem das espécies arbóreas e palmeiras encontradas em 21 praças no município Nossa Senhora do Socorro, SE

Table 2. Botanical family, scientific name, popular name and origin of the tree species and palms found out in 21 main squares of Nossa Senhora do Socorro, SE

\begin{tabular}{|c|c|c|c|c|}
\hline $\begin{array}{l}\text { Família } \\
\text { Botânica }\end{array}$ & Nome Científico & Nome Popular & $\begin{array}{c}\mathrm{N}^{\circ} \mathrm{de} \\
\text { indivíduos }\end{array}$ & Origem \\
\hline \multirow{3}{*}{ Anacardiaceae } & Anacardium occidentale L. & cajueiro & 1 & nativa \\
\hline & Mangifera indica L. & mangueira & 10 & exótica \\
\hline & Schinus terebinthifolius Raddi & aroeira & 1 & nativa \\
\hline Malvaceae & Pachira aquatica Aubl. & $\begin{array}{l}\text { castanheira-do- } \\
\text { maranhão }\end{array}$ & 5 & nativa \\
\hline Combretaceae & Terminalia catappa L. & amendoeira & 38 & exótica \\
\hline \multirow{5}{*}{ Fabaceae } & Tamarindus indica L. & tamarindo & 4 & exótica \\
\hline & Pithecellobium dulce (Roxb.) Benth. & mata-fome & 23 & exótica \\
\hline & Acacia mangium Willd & acácia & 1 & exótica \\
\hline & Clitoria fairchildiana R.A. Howard & sombreiro & 6 & nativa \\
\hline & Erythrina indica var. picta B.\&M. & brasileirinho & 8 & exótica \\
\hline Malvaceae & Hibiscus pernambucensis Arruda & $\begin{array}{l}\text { algodão-da- } \\
\text { praia }\end{array}$ & 1 & nativa \\
\hline Meliaceae & Azadirachta indica A. Juss. & neen & 5 & exótica \\
\hline Moraceae & Ficus retusa L. & fícus & 142 & exótica \\
\hline \multirow{2}{*}{ Myrtaceae } & Corymbia citriodora Hill \& Johnson & eucalipto & 1 & exótica \\
\hline & Syzygium jambolanum (Lam.) DC. & jamelão & 7 & exótica \\
\hline \multirow[b]{2}{*}{ Arecaceae } & Cocos nucifera L. & coqueiro & 17 & exótica \\
\hline & $\begin{array}{l}\text { Pritchardia pacifica Seemann \& H. } \\
\text { Wendl. }\end{array}$ & $\begin{array}{c}\text { palmeira leque- } \\
\text { de-fiji }\end{array}$ & 1 & exótica \\
\hline
\end{tabular}

Avaliando-se a diversidade de espécies em cada uma das praças analisadas, observa-se que as mais heterogêneas são: Praça Laércio Miranda, com 8 espécies e Praça da Rua 5, com 6 espécies. Já as praças: José Barreto Prado, Geraldo de Assis Silva, Leandro Silva de Souza, Antony Fernandes, Praça do SAMU e Praça do Final de Linha, apresentaram-se menos diversificadas, com a presença de apenas uma espécie em cada uma (Tabela 3). 
Tabela 3. Área, quantidade de indivíduos arbóreos, número de espécies, AB - Área basal, DA Densidade absoluta e DoA - Dominância absoluta das 21 principais praças de Nossa Senhora do Socorro - SE

Table 3. Areas, number of arboreal individuals, number of species, AB - Basal Area, DA Absolutely Density and DoA - Absolutely Dominance of the 21 main squares registered in Nossa Senhora do Socorro - SE

\begin{tabular}{|c|c|c|c|c|c|c|}
\hline Nome & $\begin{array}{l}\text { Área } \\
\left(\mathrm{m}^{2}\right)\end{array}$ & $\begin{array}{c}\text { № de } \\
\text { indivíduos }\end{array}$ & $\begin{array}{l}\text { № de } \\
\text { espécies }\end{array}$ & $\begin{array}{l}\text { AB Total } \\
\left(\mathrm{m}^{2}\right)\end{array}$ & $\begin{array}{c}\text { DA } \\
\text { (ind./ha) }\end{array}$ & $\begin{array}{c}\text { DoA } \\
\left(\mathrm{m}^{2} / \mathrm{ha}\right) \\
\end{array}$ \\
\hline Praça José Barreto Prado & 3.010 & 1 & 1 & 0,0782 & 3,322 & 0,260 \\
\hline Praça Humberto Sena & 6.734 & 22 & 4 & 3,5490 & 32,670 & 5,270 \\
\hline Praça da rua 5 & 2.993 & 17 & 6 & 2,0390 & 56,799 & 6,813 \\
\hline Praça Geraldo de Assis Silva & 2.094 & 1 & 1 & 0,0376 & 4,776 & 0,179 \\
\hline $\begin{array}{c}\text { Praça da Igreja São Marcos } \\
\text { Evangelista }\end{array}$ & 4.880 & 38 & 2 & 0,5166 & 77,869 & 1,059 \\
\hline Praça Três Inocentes & 2.646 & 12 & 3 & 0,8229 & 45,351 & 3,110 \\
\hline Praça Leandro Silva de Souza & 5.426 & 2 & 1 & 0,0025 & 3,686 & 0,005 \\
\hline $\begin{array}{c}\text { Praça do Hospital José do Prado } \\
\text { Franco }\end{array}$ & 1.077 & 13 & 2 & 0,8339 & 120,706 & 7,743 \\
\hline Praça Laércio Miranda & 3.055 & 36 & 8 & 2,3291 & 117,840 & 7,624 \\
\hline Praça da Mangabeira & 4.526 & 10 & 2 & 6,6140 & 22,095 & 14,613 \\
\hline Praça do Colégio Maria de Lourdes & 1.818 & 21 & 5 & 1,3402 & 115,512 & 7,372 \\
\hline Praça do SAMU & 370 & 2 & 1 & 0,1476 & 54,054 & 3,988 \\
\hline Praça do supermercado Todo Dia & 1.239 & 26 & 4 & 1,2323 & 209,847 & 9,946 \\
\hline Praça Hilton Lopes & 6.300 & 16 & 3 & 1,5039 & 25,397 & 2,387 \\
\hline Praça do Restaurante Popular & 6.252 & 16 & 3 & 0,4787 & 25,592 & 0,766 \\
\hline Praça do CEME & 703 & 8 & 3 & 0,0598 & 113,800 & 0,851 \\
\hline Praça Antony Fernandes & 6.702 & 1 & 1 & 0,1156 & 1,492 & 0,172 \\
\hline $\begin{array}{l}\text { Praça da capela Nossa Senhora do } \\
\text { Carmo }\end{array}$ & 8.702 & 9 & 5 & 0,3242 & 10,342 & 0,373 \\
\hline Praça do Final de Linha & 5.341 & 3 & 1 & 0,0133 & 5,617 & 0,025 \\
\hline Praça da Avenida A-51 & 5.822 & 4 & 3 & 0,4433 & 6,870 & 0,716 \\
\hline \multirow[t]{2}{*}{ Praça Santa Rosa Mística } & 1.296 & 13 & 5 & 1,4075 & 100,309 & 10,860 \\
\hline & TOTAL & 271 & 17 & & & \\
\hline
\end{tabular}

As praças que apresentaram o maior número de árvores foram: a Praça da Igreja São Marcos Evangelista com 38 indivíduos, a Praça Laércio Miranda com 36 indivíduos, a Praça do Supermercado Todo Dia com 26 indivíduos e a Praça Humberto Sena com 22 indivíduos. As praças que apresentaram a menor quantidade de indivíduos arbóreos foram: a Praça José Barreto Prado, a Praça Geraldo de Assis Silva e a Praça Antony Fernandes, com a presença de apenas um indivíduo em cada uma (Figura 1). 


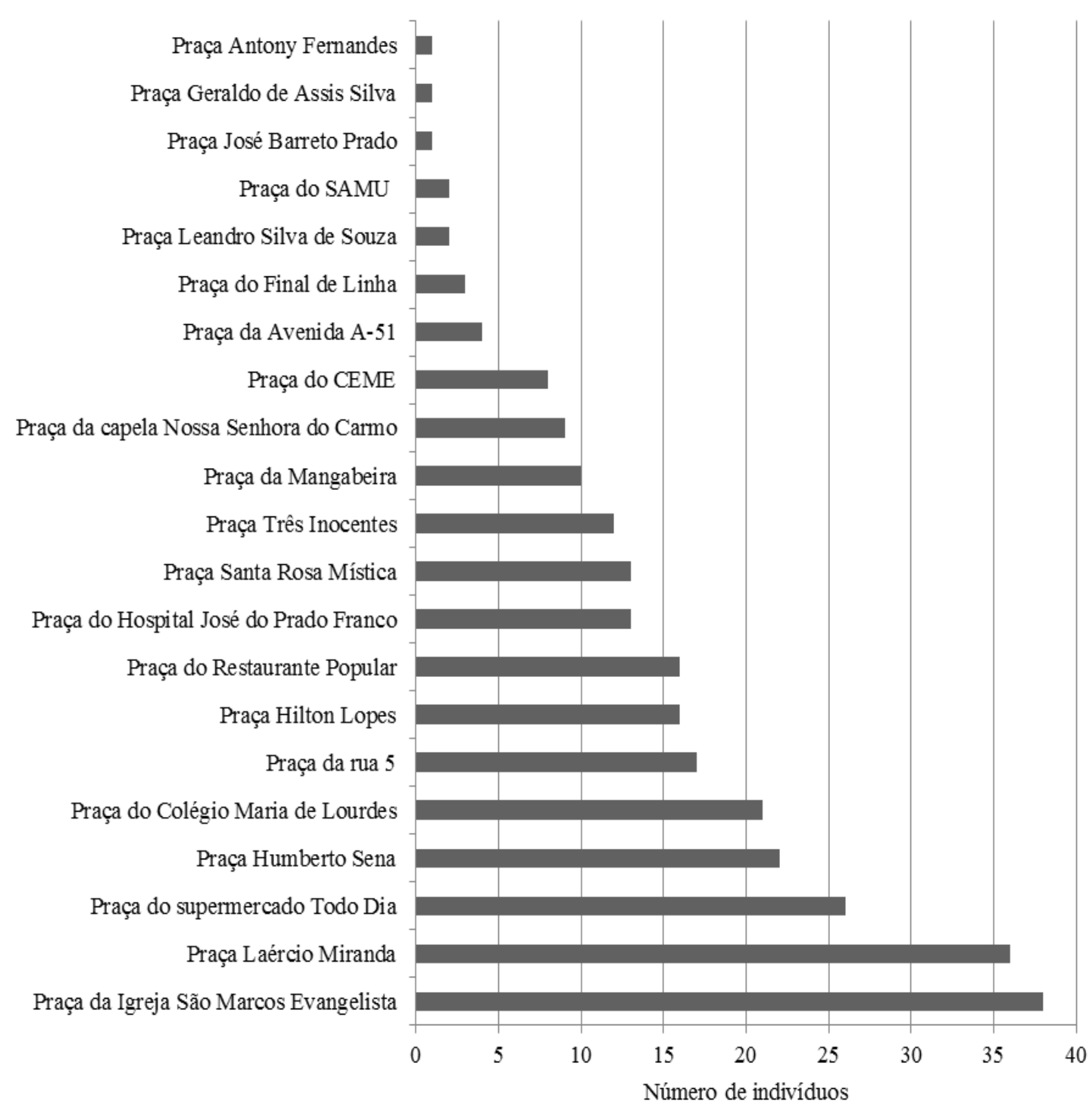

Figura 1. Quantidade de indivíduos em 21 principais praças no município de Nossa Senhora do Socorro-SE

Figure 1. Number of trees at 21 main squares located in Nossa Senhora do Socorro-SE

\section{Análise fitossociológica}

O inventário realizado nas 21 principais praças mostrou a presença de 271 indivíduos, que ocupam juntos uma área basal de $23,8 \mathrm{~m}^{2} \mathrm{~A}$ espécie Ficus retusa representou $50,4 \%$ de todos os indivíduos cadastrados, sendo verificada em 90,48 \% das praças (Tabela 4), o que indica, portanto, que existe um elevado número de indivíduos desta espécie nas praças de Nossa Senhora do Socorro, o que afeta negativamente sua diversidade florística. 
Tabela 4. Relação das espécies arbóreas localizadas em 21 principais praças analisadas, no município de Nossa Senhora do Socorro-SE, com seus respectivos parâmetros fitossociológicos

Table 4. Relation of tree species located at 21 main squares, in Nossa Senhora do Socorro, SE, with their respective phytosociological parameters

\begin{tabular}{lcccccc}
\hline \multicolumn{1}{c}{ Nome Científico } & N & AB & DA & DR & FA & FR \\
\hline Ficus retusa & 142 & 8,9001 & 17,479 & 52,40 & 90,48 & 29,69 \\
Terminalia catappa & 38 & 2,1862 & 4,677 & 14,02 & 57,14 & 18,75 \\
Mangifera indica & 10 & 6,4852 & 1,231 & 3,69 & 14,29 & 4,69 \\
Pithecellobium dulce & 23 & 2,7275 & 2,831 & 8,49 & 28,57 & 9,38 \\
Cocos nucifera & 17 & 0,6378 & 2,093 & 6,27 & 14,29 & 4,69 \\
Clitoria fairchildiana & 6 & 1,1933 & 0,739 & 2,21 & 14,29 & 4,69 \\
Syzygium jambolanum & 7 & 0,7108 & 0,862 & 2,58 & 14,29 & 4,69 \\
Azadirachta indica & 5 & 0,0475 & 0,615 & 1,85 & 14,29 & 4,69 \\
Tamarindus indica & 4 & 0,1337 & 0,492 & 1,48 & 14,29 & 4,69 \\
Erythrina indica & 8 & 0,3832 & 0,985 & 2,95 & 4,76 & 1,56 \\
Pachira aquatica & 5 & 0,2405 & 0,615 & 1,85 & 9,52 & 3,13 \\
Acacia mangium & 1 & 0,0916 & 0,123 & 0,37 & 4,76 & 1,56 \\
Anacardium occidentale & 1 & 0,0904 & 0,123 & 0,37 & 4,76 & 1,56 \\
Hibiscus pernambucensis & 1 & 0,0394 & 0,123 & 0,37 & 4,76 & 1,56 \\
Pritchardia pacifica & 1 & 0,0183 & 0,123 & 0,37 & 4,76 & 1,56 \\
Schinus terebinthifolius & 1 & 0,0031 & 0,123 & 0,37 & 4,76 & 1,56 \\
Corymbia citriodora & 1 & 0,0002 & 0,123 & 0,37 & 4,76 & 1,56 \\
\hline Total & $\mathbf{2 7 1}$ & $\mathbf{2 3 , 8 8 8 9}$ & $\mathbf{3 3 , 3 5 7}$ & $\mathbf{1 0 0}$ & $\mathbf{3 0 4 , 7 6}$ & $\mathbf{1 0 0}$ \\
\hline Legenda: N - número de indivíduos; AB - área basal; DA - densidade absoluta; DR - densidade \\
relativa (\%); FA - Freqüência Absoluta; FR - Freqüência Relativa & & &
\end{tabular}

Já a espécie que apresentou os menores valores quanto aos parâmetros fitossociológicos foi Corymbia citriodora, com apenas um indivíduo cadastrado, ocupando uma área basal de 0,0002 $\mathrm{m}^{2}$ e representando apenas $0,37 \%$ do total de indivíduos verificados, o que mostra a sua baixa utilização em projetos de arborização nas praças do município. Essa espécie apresentou Índice de Valor de Importância igual a 1,932, correspondendo a $0,64 \%$ do total para o parâmetro, enquanto a espécie Ficus retusa obteve o maior valor (119,342), corresponde a 39,78 \% do total para o parâmetro (Tabela 5).

Pode-se verificar que outras espécies também apresentaram uma grande quantidade de indivíduos, sendo bastante representativas no número total dos mesmos, tais como: Terminalia catappa (38), Pithecellobium dulce (23) e Cocos nucifera (17). Porém, isso não significa que essas espécies são as mais importantes, uma vez que obtiveram IVI de, respectivamente, 41,924; 29,280 e 13,631. Isso pode ser evidenciado com o resultado encontrado para Mangifera indica, que teve apenas 10 indivíduos cadastrados e um IVI de 35,525, configurando-se como o terceiro maior valor, superando essas duas últimas espécies de maiores densidade e frequência. 
Tabela 5. Relação das espécies arbóreas localizadas em 21 principais praças analisadas, no município de Nossa Senhora do Socorro-SE, com os parâmetros fitossociológicos

Table 5. Relation of tree species located at 21 main squares, in Nossa Senhora do Socorro, SE, with the phytosociological parameters

\begin{tabular}{lllllll}
\hline Nome Científico & DoA & DoR & IVC & IVC (\%) & IVI & IVI (\%) \\
\hline Ficus retusa & 1,096 & 37,26 & 89,655 & 44,83 & 119,342 & 39,78 \\
Terminalia catappa & 0,269 & 9,15 & 23,174 & 11,59 & 41,924 & 13,97 \\
Mangifera indica & 0,798 & 27,15 & 30,838 & 15,42 & 35,525 & 11,84 \\
Pithecellobium dulce & 0,336 & 11,42 & 19,905 & 9,95 & 29,280 & 9,76 \\
Cocos nucifera & 0,079 & 2,67 & 8,943 & 4,47 & 13,631 & 4,54 \\
Clitoria fairchildiana & 0,147 & 5,00 & 7,209 & 3,60 & 11,897 & 3,97 \\
Syzygium jambolanum & 0,087 & 2,98 & 5,558 & 2,78 & 10,246 & 3,42 \\
Azadirachta indica & 0,006 & 0,20 & 2,044 & 1,02 & 6,731 & 2,24 \\
Tamarindus indica & 0,016 & 0,56 & 2,036 & 1,02 & 6,723 & 2,24 \\
Erythrina indica & 0,047 & 1,60 & 4,556 & 2,28 & 6,118 & 2,04 \\
Pachira aquatica & 0,030 & 1,01 & 2,852 & 1,43 & 5,977 & 1,99 \\
Acacia mangium & 0,011 & 0,38 & 0,752 & 0,38 & 2,315 & 0,77 \\
Anacardium occidentale & 0,011 & 0,38 & 0,747 & 0,37 & 2,310 & 0,77 \\
Hibiscus pernambucensis & 0,005 & 0,16 & 0,534 & 0,27 & 2,096 & 0,70 \\
Pritchardia pacifica & 0,002 & 0,08 & 0,446 & 0,22 & 2,008 & 0,67 \\
Schinus terebinthifolius & 0,000 & 0,01 & 0,382 & 0,19 & 1,944 & 0,65 \\
Corymbia citriodora & 0,000 & 0,00 & 0,370 & 0,18 & 1,932 & 0,64 \\
\hline Total & $\mathbf{2 , 9 4 0}$ & $\mathbf{1 0 0}$ & $\mathbf{2 0 0}$ & $\mathbf{1 0 0}$ & $\mathbf{3 0 0}$ & $\mathbf{1 0 0}$ \\
\hline Legenda: DoA - dominância absoluta; DoR - dominância relativa; IVC - índice de valor de cobertura; IVC \\
(\%)- índice de valor de cobertura em porcentagem; IVI - índice de valor de importância; IVI (\%) - índice de \\
valor de importância em porcentagem
\end{tabular}

Segundo Scipioni (2008), isso é explicado pelo fato de que mesmo tendo um menor número de indivíduos, Mangifera indica apresentou maiores diâmetros que as outras espécies analisadas e, uma área basal de $6,4852 \mathrm{~m}^{2}$, resultando em um valor de dominância igual a 0,789 , o que equivale a $27,15 \%$ do total, colocando-a como sendo a segunda maior entre as espécies analisadas. Consequentemente, isto levou a uma maior dominância relativa e, mesmo que a Mangifera indica tenha apresentado uma menor densidade que as espécies comparadas, essa dominância proporcionou um alto valor de IVI.

O mesmo pode ser visto nas espécies de menor representatividade: Anacardium occidentale, Acacia mangium, Hibiscus pernambucensis, Pritchardia pacifica, Schinus terebinthifolius e Corymbia citriodora que apresentaram um indivíduo cada e mesmo assim obtiveram diferentes valores de IVI, sendo que o maior valor foi da Acacia mangium com 2,315 e o menor da Corymbia citriodora, com 1,932.

Ainda quanto ao Índice de Valor de Importância, apenas três espécies (Ficus retusa, Terminalia catappa e Mangifera indica) detiveram 65,59 \% do total para o parâmetro, enquanto as outras 14 espécies representaram apenas $34,41 \%$, o que mostra a maior 
distância quanto aos valores de dominância, frequência e densidade relativa dessas três espécies (Figura 2).

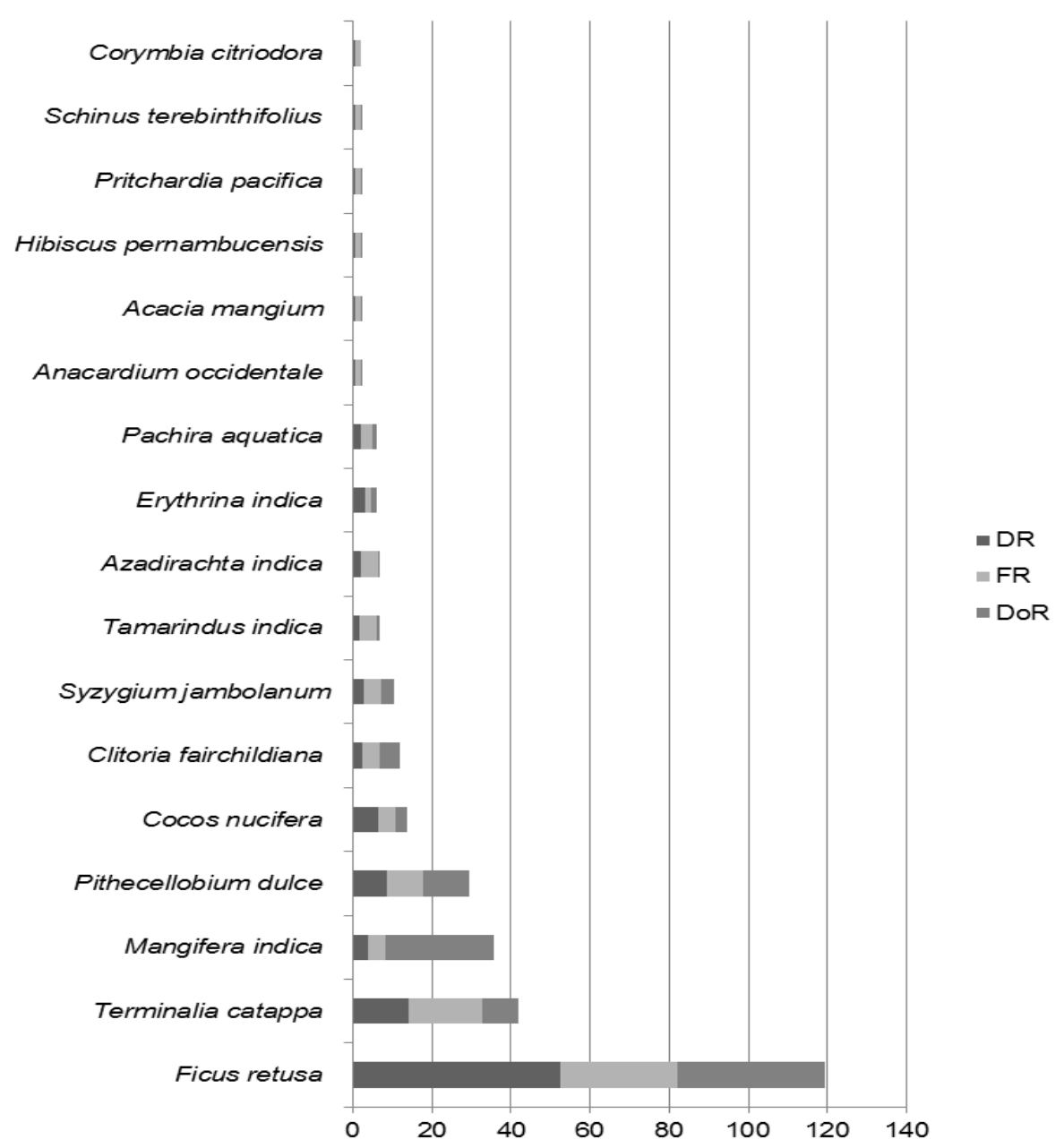

Figura 2. Distribuição do índice de valor de importância (IVI) das espécies arbóreas encontradas em 21 principais praças do município de Nossa Senhora do Socorro - SE. O valor de IVI da espécie está representada em ordem crescente pelos três parâmetros fitossociológicos

Figure 2. Importance value index (IVI) distribution of the tree species found out at 21 main squares of Nossa Senhora do Socorro, SE. The IVI value of the specie is represented by the three phytosociological parameters

É importante destacar que as espécies Ficus retusa e Terminalia catappa representaram $66,42 \%$ de todos os indivíduos existentes nas praças estudadas, e juntas, correspondem a 53,75 \% do Índice Total do Valor de Importância, mostrando a dependência dos projetos de paisagismo do município, com base apenas em duas espécies.

As espécies que apresentaram a maior densidade (Ficus retusa, Terminalia catappa, Pithecellobium Dulce, Cocus nucifera e Mangifera indica) são todas espécies exóticas e correspondem a $84,87 \%$ do total de indivíduos cadastrados em todas as praças, sendo estas as espécies que também possuem os maiores valores de frequência, ou seja, 
são encontradas em 90,48 \%, 57,14 \%, 28,57 \%, 14,29 \% e 14,29 \% das praças, respectivamente.

De acordo com os valores obtidos com a análise florística e fitossociológica, podese inferir que o modelo utilizado para a implantação de praças no município analisado não é adequado, uma vez que houve uma baixa diversidade entre as espécies arbóreas, o que segundo Silva Filho e Bortoleto (2005), é notável no planejamento da arborização urbana, apesar da variedade da flora nativa de cada região.

Dessa forma, os projetos urbanísticos, em especial de arborização, precisam contemplar não apenas a localização das praças na malha urbana, mas também a riqueza e a diversidade das espécies arbóreas a serem introduzidas (BARROS; VIRGILIO, 2003).

Além desses dois aspectos, outro de grande questionamento, é a relação entre o uso de espécies nativas e exóticas. O município estudado apresentou uso excessivo de espécies exóticas nas praças refletindo a ausência de preocupação com a conservação da flora nativa (RESENDE; SANTOS, 2010).

Apesar da adoção de espécies exóticas não ser tecnicamente a mais indicada para os projetos de arborização, já que as espécies nativas garantem a identidade biológica da região, oferecendo também abrigo e alimentação à fauna local e, desta forma, protegendo os ecossistemas onde estão inseridas (DANTAS; SOUZA, 2004), a presença de grande quantidade dessas espécies é comum aos ambientes urbanos como a arborização no município de Araçoiaba da Serra, interior do Estado de São Paulo (GRACIANO-SILVA; CARDOSO-LEITE; TONELLO, 2014), no centro da cidade de São Joaquim, no Estado de Santa Catarina (SOUZA et al., 2014), e nas ruas da cidade de Curitiba, Estado do Paraná (BOBROWSKI; BIONDI, 2014).

Além da devida atuação da gestão pública nas áreas verdes, a própria população também pode participar das atividades de arborização urbana, seja no plantio de mudas adequadas em frente às suas residências ou na manutenção e conservação da arborização implantada pelos órgãos públicos (MORAES; MACHADO, 2014).

Assim, todas estas etapas do planejamento referente à arborização urbana devem ser conhecidas e seguidas por gestores e pela população, à qual devem ser destinadas políticas públicas ligadas à educação ambiental, a fim de que possa haver sucesso em plantios futuros e maximização dos benefícios gerados pela arborização (GRACIANOSILVA; CARDOSO-LEITE; TONELLO, 2014). 


\section{CONCLUSÕES}

As 21 principais praças analisadas no município de Nossa Senhora do Socorro SE apresentaram uma baixa diversidade de espécies (17), sendo 70,5\% exóticas e apenas $29,5 \%$ nativas.

As espécies com maior número de indivíduos foram: Ficus retusa, Terminalia catappa, Pithecellobium dulce e Cocos nucifera. Já as menos representativas e as de menor frequência são: Acacia mangium, Anacardium occidentale, Corymbia citriodora, Hibiscus pernambucensis, Pritchardia pacifica e Schinus terebinthifolius.

A baixa diversidade de espécies e o elevado número de indivíduos de Ficus retusa e Terminalia catappa podem ocasionar problemas futuros, em caso de surgimento de pragas e doenças que estas espécies nãos sejam resistentes. Ou ainda, pode surgir a necessidade de se substituir um grande número de indivíduos, quando estas completarem o seu ciclo de vida.

\section{REFERÊNCIAS}

BARROS, M. V. F.; VIRGILIO, H. Praças: espaços verdes na cidade de Londrina. Revista GEOGRAFIA, Londrina, v. 12, n. 1, p. 533-544, 2003.

BOBROWSKI, R.; BIONDI, D. Gestão da arborização de ruas - estudo de caso na cidade de Curitiba, PR. Revista da Sociedade Brasileira de Arborização Urbana, Piracicaba, v. 9, n. 4, p. 132-150, 2014.

BRITO, D. R.S.; RAABE, J.; SOUSA, W. C.; MELO, R. R.; PEDROSA, T. D. Diagnóstico da arborização das praças pública no município de Bom Jesus, Piauí. Revista Scientia Plena, Aracaju, v. 8, n. 4 (b), p. 1-6, 2012.

COLETTO, E. P.; MÜLLER, N. G.; WOLSKI, S. S. Diagnóstico da arborização das vias públicas do município de Sete de Setembro-RS. Revista da Sociedade Brasileira de Arborização Urbana, Piracicaba, v. 3, n. 2, p. 110-122, 2008.

DANTAS, I. C.; SOUZA, C. M. C. de. Arborização urbana na cidade de Campina Grande PB: Inventário e suas espécies. Revista de Biologia e Ciências da Terra, Campina Grande, v. 4, n. 2, 2004, n/p.

EMBRAPA. Mapa de Reconhecimento de Solos do município de Nossa Senhora do Socorro, SE. Disponível em: <http://www.uep.cnps.embrapa.br/solos/se/nossasenhora dosocorro.pdf> Acesso em: 10 ago. 2010.

FREITAS, W. K.; MAGALHÃES, L. M. S. Métodos e Parâmetros para Estudo da Vegetação com Ênfase no Estrato Arbóreo. Floresta e Ambiente, Rio de Janeiro, v. 19, n. 4, p. 520540, 2012. 
GRACIANO-SILVA, T.; CARDOSO-LEITE, E.; TONELLO, K. C. Inventário da arborização urbana no município de Araçoiaba da Serra, SP. Revista da Sociedade Brasileira de Arborização Urbana, Piracicaba, v. 9, n. 4, p. 151-169, 2014.

GROSTEIN, M. D. Metrópole e expansão urbana a persistência de processos "insustentáveis". São Paulo em Perspectiva, São Paulo, v. 15, n. 1, p. 13-19, 2001.

IBGE. Instituto Brasileiro de Geografia e Estatística. Cidades @. Sergipe. Disponível em: $<$ http://www.ibge.gov.br/cidadesat/xtras/perfil.php?codmun=280480\&search=sergipe|nossasenhora-do-socorro> Acesso em: 10 ago. 2011 a.

IBGE. Instituto Brasileiro de Geografia e Estatística. Mapas interativos de biomas. Disponível em: <http://mapas.ibge.gov.br/biomas2/viewer.htm> Acesso em: 09 dez. 2011b.

MORAES, A. F.; GOUDARD, B.; OLIVEIRA, R. Reflexões sobre a cidade, seus equipamentos urbanos e a influência destes na qualidade de vida da população. Revista Internacional Interdisciplinar INTERthesis, Florianópolis, v. 5, n. 2, p. 93-103, 2008.

MORAES, L. A.; MACHADO, R. R. B. A arborização urbana do município de Timon/MA: inventário, diversidade e diagnóstico quali-quantitativo. Revista da Sociedade Brasileira de Arborização Urbana, Piracicaba, v.9, n.4, p. 80-98, 2014.

REFLORA. Lista de espécies da flora do Brasil, 2012. Disponível em: $<$ http://reflora.jbrj.gov.br/jabot/listaBrasil/ConsultaPublicaUC/ConsultaPublicaUC.do> Acesso em: 02 jan. 2013.

RESENDE, M. T.; SANTOS, D. G. Avaliação quali-quantitativa da arborização das praças do bairro Jaraguá, Uberlândia-MG. Revista da Sociedade Brasileira de Arborização Urbana, Piracicaba, v. 5, n. 2, p. 139-157, 2010.

REDING, C. G.; VOGEL, C.; TROJAHN, C. D. P.; GRACIOLI, S. J. L. Análise da arborização urbana em cinco praças do município de Cachoeira do Sul, RS. Revista Brasileira de Arborização Urbana, Piracicaba, v. 5, n. 3, p. 149-164, 2010.

ROXO, F. F.; BICUDO, L. R. H.; DINIZ, R. E. Da S. Levantamento florístico da praça Coronel Moura, Bitucatu, SP. Revista Ciência em Extensão, São Paulo, v. 5, n. 1, p. 106112, 2009.

SCIPIONI, M. C. Análise dos padrões florísticos e estruturais da comunidade arbóreaarbustiva e da regeneração natural em gradientes ambientais da floresta estacional, RS, Brasil. Santa Maria, 2008. 146f. Dissertação (Mestrado em Engenharia Florestal) Universidade Federal de Santa Maria, Santa Maria, 2008.

SERRANO, D. G.; AGASSI, J. D.; BARBOSA, L. C.; OLIVEIRA, V. H. M.; SIMÕES, F. A. Gestão pública dos espaços vazios do município de Sarandi/PR. Revista de Engenharia e Tecnologia, Ponta Grossa, v. 2, n. 3, p. 114-124, 2010.

SILVA FILHO, D. F.; BORTOLETO, S. Uso de indicadores de diversidade na definição de plano de manejo da arborização viária de Águas de São Pedro SP. Revista Árvore, Viçosa, v. 29 , n. 6 , p. 973-982, 2005.

SOCORRO. PREFEITURA MUNICIPAL DE NOSSA SENHORA DO SOCORRO. A cidade. Disponível em: <http://www.socorro.se.gov.br/a-cidade> Acesso em: 13 ago. 2011. 
SOUZA, A. L. L. de; FERREIRA, R. A.; MELLO, A. A. de; PLÁCIDO, D. R.; SANTOS, C. Z. A. dos; GRAÇA, D. A. S. da; ALMEIDA JÚNIOR, P. P. de; BARRETTO, S. S. B.; DANTAS, J. D. M.; PAULA, J. W. A. de; SILVA, T. L. da; GOMES, L. P. S. Diagnóstico quantitativo e qualitativo da arborização das praças de Aracaju, SE. Revista Árvore, Viçosa, v. 35, n. 6, p. 1253-1263, 2011.

SOUZA, P. F.; BOURSCHEID, C. B.; POMPEÓ, P. N.; STANG, M. B.; MANFROI, J.; RODRIGUES, M. D. S.; SILVA, A. C.; HIGUCHI, P. Revista da Sociedade Brasileira de Arborização Urbana, Piracicaba, v. 9, n. 4, p. 99-112, 2014.

TISCHER, J. C.; FORTE, A. R.; PEDROSO-DE-MORAES, C. Análise qualiquantitativa de indivíduos arbóreos das praças centrais do município de Leme, SP. Revista da Sociedade Brasileira de Arborização Urbana, Piracicaba, v. 9, n. 3, p. 49-64, 2014.

TOLEDO, F.S.; SANTOS, D.G. Espaços livres de construção. Revista da Sociedade Brasileira de Arborização Urbana, Piracicaba, v. 3, n. 1, p. 73-91, 2008. 